\title{
Study of the Radical Chain Mechanism of Hydrocarbon Oxidation for In Situ Combustion Process
}

\author{
Alexandra Ushakova, ${ }^{1}$ Vladislav Zatsepin, ${ }^{2}$ Mikhail Varfolomeev, ${ }^{1}$ and Dmitry Emelyanov ${ }^{1}$ \\ ${ }^{1}$ Department of Physical Chemistry, Kazan Federal University, Kremlevskaya Str. 18, 420008 Kazan, Russia \\ ${ }^{2}$ Institute of Geology and Petroleum Technologies, Kazan Federal University, Kremlevskaya Str. 18, 420008 Kazan, Russia
}

Correspondence should be addressed to Alexandra Ushakova; paravoz-s@yandex.ru

Received 16 September 2016; Revised 25 December 2016; Accepted 9 January 2017; Published 6 March 2017

Academic Editor: Tran X. Phuoc

Copyright (C) 2017 Alexandra Ushakova et al. This is an open access article distributed under the Creative Commons Attribution License, which permits unrestricted use, distribution, and reproduction in any medium, provided the original work is properly cited.

\begin{abstract}
Despite the abundance of in situ combustion models of oil oxidation, many of the effects are still beyond consideration. For example, until now, initial stages of oxidation were not considered from a position of radical chain process. This is a serious difficulty for the simulation of oil recovery process that involves air injection. To investigate the initial stages of oxidation, the paper considers the sequence of chemical reactions, including intermediate short-living compounds and radicals. We have attempted to correlate the main stages of the reaction with areas of heat release observed in the experiments. The system of differential equations based on the equations of oxidation reactions was solved. Time dependence of peroxides formation and start of heat release is analytically derived for the initial stages. We have considered the inhibition of initial oxidation stages by aromatic oil compounds and have studied the induction time in dependence on temperature. Chain ignition criteria for paraffins and crude oil in presence of core samples were obtained. The calculation results are compared with the stages of oxidation that arise by high-pressure differential scanning calorimetry. According to experimental observations we have determined which reactions are important for the process and which can be omitted or combined into one as insignificant.
\end{abstract}

\section{Introduction}

Air injection is a promising enhanced oil recovery method, in which compressed air is injected into oil reservoir with the expectation that oil oxidation will lead to the hightemperature combustion front formation and oil effective displacement [1]. It has already been applied in numerous types of reservoirs of light and heavy oil as well. The most technically and economically successfully field implementations are going on from twenty to forty years [2].

The air injection EOR method is based on oil in situ oxidation when it contacts with compressed oxygen in porous media. The reservoir conditions and oil properties determine the rate of oxidation which leads to the combustion front formation. The efficiency and safety of air injection depend on the combustion front stability.

In general oxidation of crude oil can be divided into low-temperature and high-temperature oxidation (LTO and HTO reactions) [1]. The intensity of oxidation and the transition from LTO to HTO mainly depends on the reservoir temperature and pressure.

Usually for heavy oil reservoirs pressure is from 1-5 MPa and temperature from $20-50^{\circ} \mathrm{C}$. In such case that oxidation of crude oil on contact with atmospheric oxygen may occur very slowly, the process cannot go into the combustion stage (HTO) and end as the LTO stage and transformation of crude oil into oxidized high-molecular compounds. The transition from LTO to HTO reactions needs additional heating or artificial ignition.

For light oil and high-pressure reservoirs (15-30 MPa) the initial temperature is higher, $80-95^{\circ} \mathrm{C}$. For this kind of oils ignition usually occurred without the artificial initiation of combustion: Delhi $-57^{\circ} \mathrm{C}, 40^{\circ} \mathrm{API}$ [3], Buffalo $-93^{\circ} \mathrm{C}, 32^{\circ} \mathrm{API}$, [4], and Gnedintsy, $48^{\circ} \mathrm{C}, 32^{\circ} \mathrm{API}$ [5].

There are also some heavy oil deposits, where oil is active enough to occur spontaneous combustion: Pavlova Gora, $28^{\circ} \mathrm{C}, 18^{\circ} \mathrm{API}[6]$ and California oilfields about $37^{\circ} \mathrm{C}, 15^{\circ} \mathrm{API}$ [7]. In the history of field development with the help of air 
injection there are cases where self-ignition of low-viscosity, light oil did not occur, such as Arlankovsky field $24^{\circ} \mathrm{C}, 30^{\circ} \mathrm{API}$ [8]. There was no ignition of the oil from Salymsky oilfield, $82^{\circ} \mathrm{C}, 40^{\circ} \mathrm{API}$ during the experiments in the ARC [9].

Thus one can see that spontaneous ignition has nonobvious dependence on the reservoir temperature and oil gravity. The main conclusions on the impact of the different characteristics of the oil reservoir to initiate combustion are the following: the higher the temperature and pressure in the formation, the greater the risk of ignition; light oil ignites faster than heavy oil, but there are enough exceptions, mentioned above.

There are numerous types of models of crude oil oxidation which demonstrate the stable combustion process; gas output, the amount of fuel for combustion, and temperature rise.

On the basis of field experience, it may be noted that some regularities of various factors influence on the initiation of combustion were identified empirically without defining their mutual influence. Also, the mechanism of crude oil selfignition in reservoir conditions allowing building a reliable model of the process is not identified.

\section{The Mechanism of Low-Temperature and High-Temperature Oxidation}

According to the literature, the rate-limiting step of the oxidation process is the accumulation of hydroperoxides [10]. The formation of hydroperoxide is a key stage of the process; at first oxygen penetrates into the oil chains (this stage takes place at any temperature) and forms free radicals and radicals are passed from one molecule to another (chain growth), until they form hydroperoxide. Hydroperoxides can decompose into a pair of radicals; this is a branching chain reaction. Such reactions rarely occur in hydrocarbons (chain branching factor is small, so the oxidation of hydrocarbons is called the oxidation with degenerate chain branching).

Next is the destruction of free radicals with the formation of oxidation products. Products are oxidized compounds, acid aldehydes, ketones, or $\mathrm{CO}, \mathrm{CO}_{2}$, and water. The process of low-temperature and then the high-temperature oxidation begins with consumption of peroxides. Another variant of oxidation is a high-temperature oxidation where chain mechanism takes place, but it is not the main one. At high temperatures, peroxide decomposes without radical mechanism [10].

Thus, the initial stages have the same mechanism regardless of the temperature, a radical chain mechanism, and hightemperature oxidation can occur by two different mechanisms. Nonradical peroxide decomposition takes place at high temperature, above $250^{\circ} \mathrm{C}$, and radical decomposition may also occur at a low temperature (lower that $50^{\circ} \mathrm{C}$ ) and may stay unfinished.

For the first time, in a theoretical paper [11] an attempt to describe the oxidation kinetics of in situ combustion within the idea of the radical chain mechanism of aliphatic hydrocarbon oxidation reactions was made.
There are several interesting conclusions in the paper; assuming these conclusions we are building our model of oxidation.

(i) It is shown that oil oxidation occurs with the formation of intermediates, hydroperoxides. At insufficiently high temperatures, oxidation ends at this stage.

(ii) Isomerization and decomposition reactions occur at higher temperatures; $\mathrm{CO}_{2}$ and $\mathrm{CO}$ can be released at this stage. Decomposition reaction dominates at temperatures above $500^{\circ} \mathrm{C}$, resulting in complete combustion with formation of $\mathrm{CO}_{2}$ and $\mathrm{H}_{2} \mathrm{O}$.

(iii) Crude oil contains aromatic compounds which act as inhibitors of the initial stages of oxidation. Inhibitors become inactive at temperatures of $180-220^{\circ} \mathrm{C}$. Aromatic oxidized compounds are not decomposed as long as the temperature does not rise to the HTO $\left(350^{\circ} \mathrm{C}\right)$. Below this temperature, only these compounds continue to be oxidized, forming oxidized heavy residue, which is a fuel for high-temperature combustion.

(iv) There is an area of the negative temperature gradient. Oxidation in the gas phase through this area occurs before the liquid phase. The negative temperature gradient arises due to overlapping of peroxides formation effects and their decomposition with the release of gas and the formation of oxidized heavy residue.

(v) Complexity of the heavy oil reservoir ignition is explained by overlaying of inhibition and stabilization of oxidized compounds in the area of negative gradient, further oxidation of which is inhibited by insufficient temperature.

Further we analyze different types of reaction in order to derive the most complete and common set of chemical reactions.

2.1. Initiation of the Oxidation. Studies of hydrocarbon oxidation with oxygen suggest that oxidation always proceeds with a separation of the $\mathrm{C}-\mathrm{H}$ bond, both in branched chain and in unbranched process [12]. Liquid hydrocarbons are resistant to dissociation of the $\mathrm{C}-\mathrm{C}$ bond up to $200^{\circ} \mathrm{C}$. If oxidation is initiated without specific molecular reaction initiator, such initiation is called autoxidation of oil. Bimolecular initiation reaction is as follows:

$$
\mathrm{Oil}+\mathrm{O}_{2} \stackrel{k_{1}}{\longrightarrow} \mathrm{R}^{*}+\mathrm{HOO}^{*}
$$

$\mathrm{R}^{*}$ is the alkyl radical. Initiation rate depends on the following concentrations: $v_{0}=k_{1} C_{\mathrm{Oil}} C_{\mathrm{O}_{2}}$.

Intramolecular initiation reaction can occur in case of liquid phase oxidation: $\mathrm{Oil}+\mathrm{O}_{2}+\mathrm{Oil} \stackrel{k_{0}^{\prime}}{\longrightarrow} 2 \mathrm{R}^{*}+\mathrm{H}_{2} \mathrm{O}_{2}$. Then, the reaction rate can be written as $v_{0}^{\prime}=k_{0}^{\prime} C_{\mathrm{Oil}^{2}}^{2} C_{\mathrm{O}_{2}}$. The activation energies of the first and second reactions, respectively, are $197 \mathrm{~kJ} / \mathrm{mol}$ and $577 \mathrm{~kJ} / \mathrm{mol}$. The probability of the first reaction is higher than the second one due to the gain in energy, but it is possible to check the implemented mechanism when determining the order of initiation reaction by fuel. 
2.2. The Formation of Peroxides. Free radicals again enter into the chain propagation reactions, which can be written as in [11]:

$$
\begin{gathered}
\mathrm{R}^{*}+\mathrm{O}_{2} \stackrel{k_{2}}{\longrightarrow} \mathrm{RO}_{2}^{*} \\
\mathrm{Oil}+\mathrm{RO}_{2}^{*} \stackrel{k_{3}}{\longrightarrow} \mathrm{R}^{*}+\mathrm{P}
\end{gathered}
$$

$\mathrm{RO}_{2}^{*}$ is the alkyl peroxyl radical. $\mathrm{P}=\mathrm{ROOH}-$ hydroperoxide radicals react almost instantly after the formation, as their activation energy is very small. According to [10], the rate constant of this reaction amounts to 105-108 liter/(mol*s). Therefore, the chain growth stage is regulated by radical formation rate. Then radicals form hydroperoxide. Hydroperoxides are major oxidation products at early stages of the process. They are formed from a wide variety of oil compounds undergoing oxidation. The bond strength of $\mathrm{O}-\mathrm{O} \sim 160-200 \mathrm{~kJ} / \mathrm{mol}$ is inferior to bond strengths of $\mathrm{O}-\mathrm{H}(\sim 480 \mathrm{~kJ} / \mathrm{mol})$ and $\mathrm{O}-\mathrm{C}(\sim 380 \mathrm{~kJ} / \mathrm{mol})$; therefore peroxides are the most unstable from oxygen-containing oil compounds.

2.3. The Decomposition of Peroxides. The hydrocarbon hydroperoxides can actively participate in the oxidation process. Thermal decomposition of hydroperoxides can proceed by a monomolecular mechanism on two free radicals by the following reaction:

$$
\mathrm{P} \stackrel{k_{4}}{\longrightarrow} \mathrm{RO}^{*}+{ }^{*} \mathrm{OH}
$$

The kinetic equation of such decomposition is first order. Hydroperoxides may accumulate in the system, especially if temperature is low $\left(100-200^{\circ} \mathrm{C}\right)$ and hydroperoxides can react by [10] as $\mathrm{P}+\mathrm{P} \rightarrow \mathrm{RO}_{2}^{*}+\mathrm{RO}^{*}+\mathrm{H}_{2} \mathrm{O}$. The kinetic equation of such decomposition is second order; it goes slowly and is not included into the main set of reactions. But on the other hand there are experiments that have shown water existence at the initial stages of oxidation. The process of water appearance is sometimes called "waste of hydrogen" [1] that can be expressed in reaction [13]:

$$
\mathrm{P}+\mathrm{Oil} \stackrel{k_{5}}{\longrightarrow} \mathrm{RO}^{*}+\mathrm{R}^{*}+\mathrm{H}_{2} \mathrm{O}
$$

According to EPR-spectroscopy experiments the concentration of organic radicals got by the hydroperoxides decomposition increased twice with the temperature growth (from $4.5 * 10^{6} \mathrm{spin} / \mathrm{g}$ at $60^{\circ} \mathrm{C}$ to $8.4 * 10^{6} \mathrm{spin} / \mathrm{g}$ at $170^{\circ} \mathrm{C}$ ). For grater temperatures the amount of free radicals reaches dynamic equilibrium.

From temperature more than $200^{\circ} \mathrm{C}$ hydroperoxides also decompose by nonradical mechanism with the release of $\mathrm{CO}$ $\mathrm{CO}_{2}$ and water.

$$
\mathrm{P} \stackrel{k_{6}}{\longrightarrow} \mathrm{CO}_{2}+\mathrm{CO}+\mathrm{H}_{2} \mathrm{O}
$$

Decomposition of hydroperoxide is a stage of oxidation, in the process of which dependence of reaction rate on oxygen concentration is reduced; therefore according to the authors [11], it is confined to the negative temperature gradient.

Characteristics of hydroperoxide are determined with their hydrocarbon component. Hydroperoxides of paraffinic hydrocarbons actively decompose at temperatures of 180$200^{\circ} \mathrm{C}$. This process is called degenerate chain branching and leads to an acceleration of the oxidation process.

2.4. The Formation of Alcohols, Aldehydes, and Ketones. RO* radicals come into further interaction with oil and continue new chains by the reaction:

$$
\mathrm{RO}^{*}+\mathrm{Oil} \stackrel{k_{7}}{\longrightarrow} \mathrm{R}^{*}+\mathrm{RO}-\mathrm{H}
$$

This reaction is most likely to occur in the gas phase. A quadratic break of radicals with formation of alcohols and ketones can occur by the following reactions: $\mathrm{R}^{*}+\mathrm{R}^{*} \rightarrow \mathrm{R}-\mathrm{R}$, $\mathrm{RO}_{2}^{*}+\mathrm{R}^{*} \rightarrow \mathrm{RO}-\mathrm{OR}$, or $\mathrm{RO}_{2}^{*}+\mathrm{RO}_{2}^{*} \rightarrow \mathrm{RO}-\mathrm{OR}+\mathrm{O}_{2}$. Such reactions have low activation energy of about $4 \mathrm{~kJ} / \mathrm{mol}$ and occur almost immediately after the peroxide decomposition. Radicals may also interact with alcohols and acids with the release of $\mathrm{CO}_{2}$. The oxidation rate at this stage depends on the molecular structure of the hydrocarbon moieties of alcohols, aldehydes, acids, and radicals themselves. The oxidation of the hydrocarbon molecules sequentially into hydroperoxide, alcohol, and ketone preserves the original hydrocarbon skeleton of the molecule, because $\mathrm{C}-\mathrm{C}$ bond breaking has an energy of $377 \mathrm{~kJ} / \mathrm{mol}$ [10]. Activity of radicals varies in the process of oxidation, as it depends on which hydrocarbon molecule is subjected to oxidation with the formation of a radical. If paraffin molecules are active, then aromatic compounds form phenols under the oxidation, which start to inhibit further oxidation processes. Oxidation inhibition effect begins when all the radicals have already created all possible oxidized compounds, and energy of the system is insufficient to break formed bonds (C-O, O-O, C$\mathrm{H}$, and $\mathrm{C}-\mathrm{C})$.

All processes mentioned above referred to a very small heat release during the reaction, as well as to the almost absence of $\mathrm{CO}$ and $\mathrm{CO}_{2}$ in the reaction products. At this stage the following can be observed:

(1) absorption of oxygen;

(2) formation of peroxide radicals;

(3) consumption of peroxide radicals;

(4) small release of $\mathrm{CO}$ and $\mathrm{CO}_{2}$;

(5) increase in density and viscosity of the oil, aggregation of oxidized compounds, its adsorption on the rock surface, and deposition of insoluble residue (fuel formation for further process of oxidation).

These processes are known as partial oxidation (lowtemperature oxidation). If high-temperature combustion front is not formed as a result of these processes, then accumulation of oxidation products (which are centers of free radicals' destruction) in crude oil occurs. Crude oil properties deteriorate; it becomes strongly connected with the rock and less mobile, becomes capable of forming a rigid emulsion, 

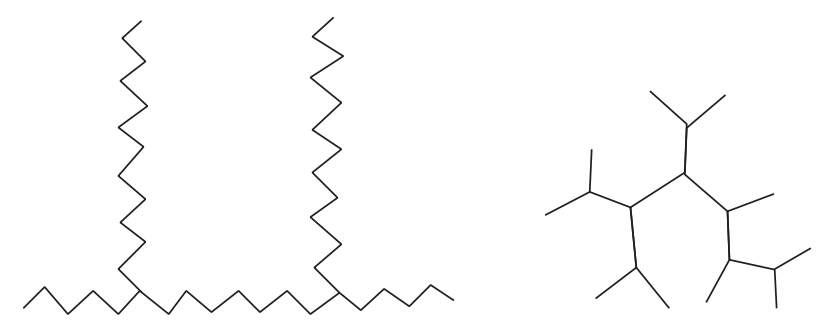

FIGURE 1: Schematic representation of a chain reaction with the rare chain branching (as hydrocarbon oxidation) and completely branched reaction (as nuclear reactions) [14].

and loses its ability to self-ignition. Depositions in the form of oxidized compounds are sometimes recovered at the field after air injection from injection well.

\subsection{Influence of Crude Oil Group Composition on the Rate of} Oxidation. The formation of peroxides and oxidized products occurs due to chain reactions (formation, growth, and destruction of free radicals) through short-lived radicals. Deceleration and acceleration of radical reactions, caused by small additions of catalysts or inhibitors, are possible at the stage of radical oxidation. Crude oil can initially contain these compounds which can be formed during the initial stages of oxidation. Most likely, features of light and heavy oil oxidation are associated with the presence of substances that affect the oxidation process at the stage of the chains growth by a radical mechanism.

Oxidation of organic compounds proceeds as a chain reaction involving the $\mathrm{R}^{*}$ and $\mathrm{RO}_{2}^{*}$ radicals at different stages and $\mathrm{RO}^{*}{ }^{*} \mathrm{OH}$ radicals from decomposed peroxides. The decomposition of peroxides greatly accelerates the oxidation as it leads to branching of chains, formation of two radicals at a time, reaction $\left(4^{\prime}\right)$ (Figure 1$)$.

Slowing down of oxidation occurs when scavenging radicals by inactive molecule, in the process of hydroperoxide decomposition without formation of radicals or during the formation of inactive peroxide. Well-known inhibitors (Ing) contained in oil are different aromatic compounds, phenol derivatives, and other substances having a benzole ring in its composition.

$$
\mathrm{RO}_{2}^{*}+\text { Ing } \stackrel{k_{8}}{\longrightarrow} \text { Ing }^{*}
$$

The earlier the inhibitor is entered into the system, the greater is its effect on the deactivation of active centers; if the crude oil contains the inhibitor initially, it starts its effect immediately and oxidation does not develop until the rate of radicals formation does not exceed the rate of inhibition, or until the whole inhibitor becomes oxidized and inactive. This effect was observed in experiments on oil-hexadecane mixture oxidation in various concentrations (Figure 2). The continuous addition of crude oil to C16 acts as inhibitor upon hexadecane oxidation.

As the temperature rises above $180^{\circ} \mathrm{C}$, some inhibitors become less active and are not able to slow down the oxidation reaction.

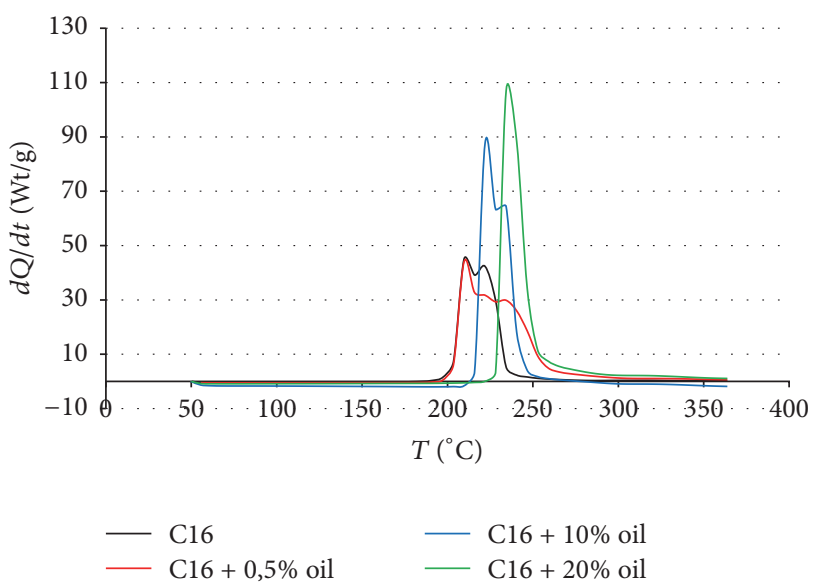

Figure 2: Heat output for hexadecane and hexadecane solutions with oil of various concentrations oxidation (inhibition effect of crude oil).

2.6. Formation of Fuel and Related Changes in the System. According to the current terminology, all substances, which burn at the second peak of heat release $\left(450-600^{\circ} \mathrm{C}\right)$, are called "fuel for combustion." Fuel, often called "coke" in the literature, is generated during the oxidation process from aromatic, cyclic, and even saturated hydrocarbons.

Therefore, according to oil composition, it can be said that resinous and aromatic fractions of crude oil provide fuel under heating in addition to asphaltenes existing in the oil.

This process is characterized by waste of hydrogen from hydrocarbon molecules, as it was obtained in TG experiments with crude oil oxidation. TG and DTG curve were obtained from the experiments with crude oil in dynamic air atmosphere $(75 \mathrm{~mL} / \mathrm{min})$ under $20 \mathrm{~K} / \mathrm{min}$ heating rate using thermogravimetry coupled with spectrometer. Figure 3(a) demonstrates the weight loss during the oxidation (three DTG peaks, first corresponds to evaporation and second and third are caused by oxidation). The hydrogen is taken away during the second weight loss peak $\left(430-480^{\circ} \mathrm{C}\right)$ which is confirmed by Figure $3(\mathrm{~b})$ where water, $\mathrm{CO}$, and $\mathrm{CO}_{2}$ are measured. Water is measured till $470^{\circ} \mathrm{C}$.

It is necessary to mention that oil oxidation under atmospheric pressure is not the same as under $5-10 \mathrm{MPa}$, because of the strong influence of evaporation, which does not occur in reservoir conditions. Thus Figure 3 demonstrates the behavior of crude oil oxidation in temperature range $400-600^{\circ} \mathrm{C}$. For lower temperature the process is very much distorted due to evaporation, which does not happen in pressurized DSC experiments.

Oil begins to demix and lose uniformity on the stage of the fuel formation. Precipitation of solids occurs in case of rock presence; that fact was studied in experiments on oil oxidation by pressurized differential scanning calorimetry (PDSC) [15]. Increase of the acid number observed at the field also indicates on oxidized, but not burnt, fractions, which present in the produced crude oil. Emulsions obtained at the field are also associated with the presence of oxidized 


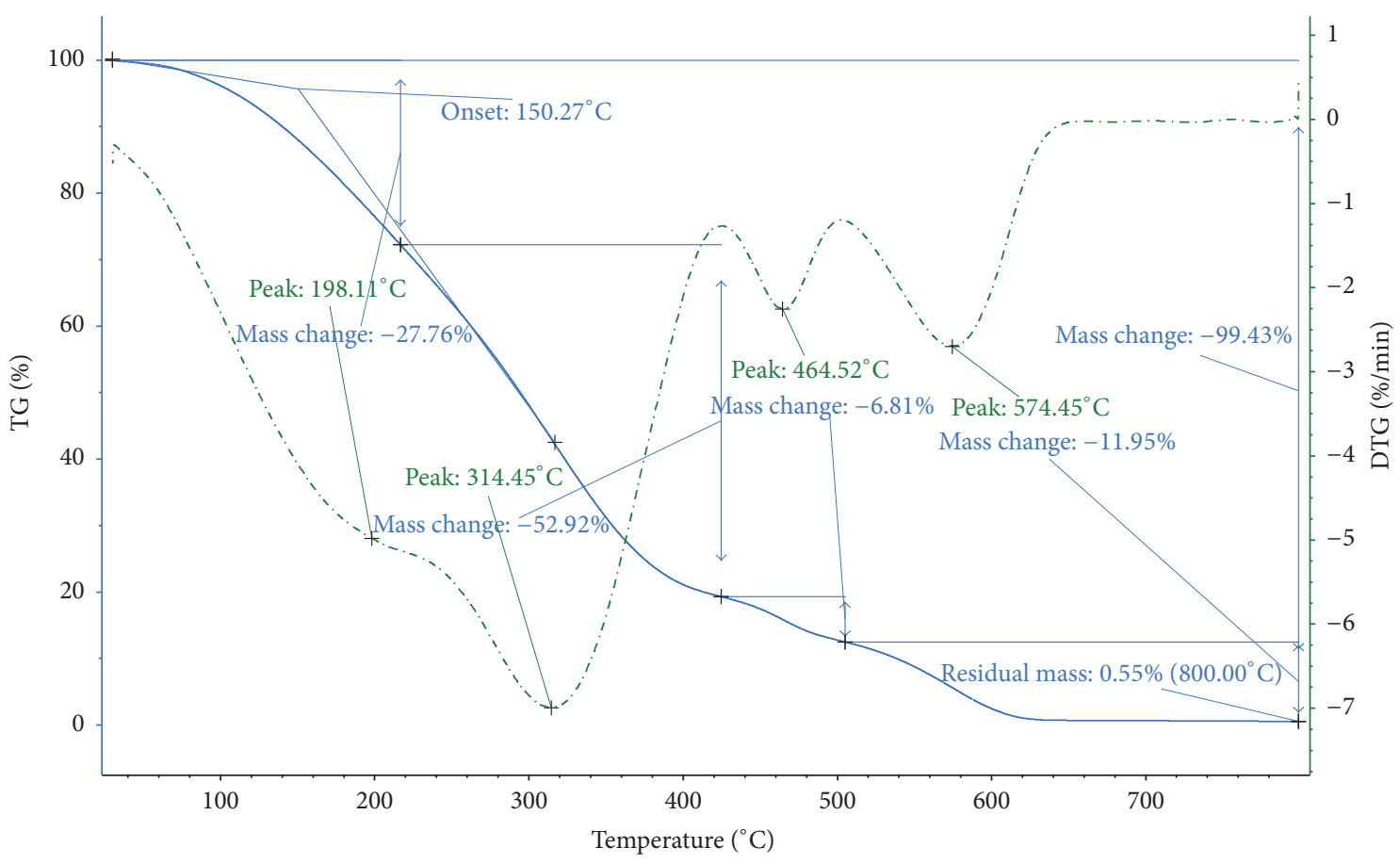

(a)

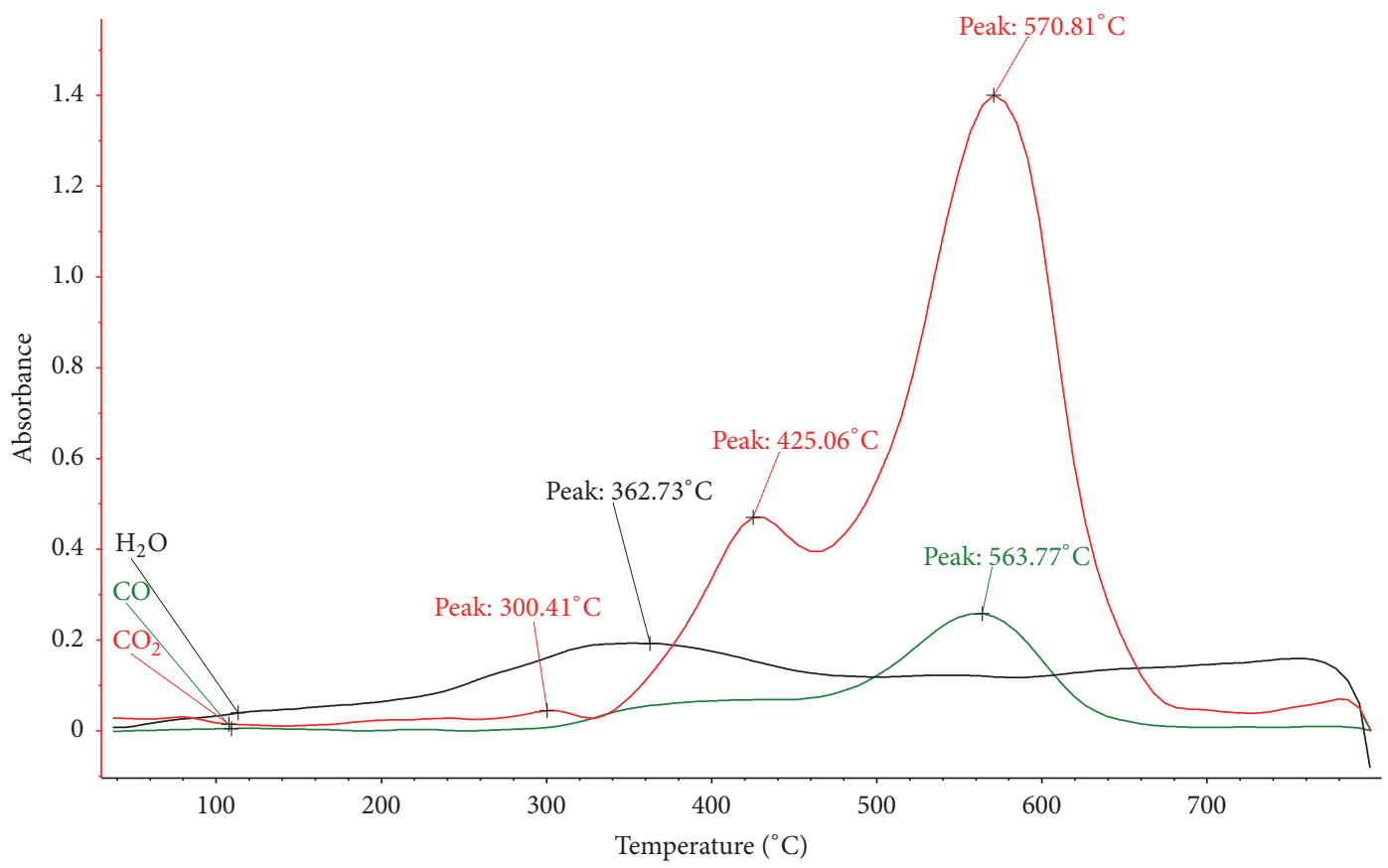

(b)

FIgURE 3: Crude oil oxidation. (a) TG and DTG of oil oxidation and (b) $\mathrm{CO}, \mathrm{CO}_{2}$, and water output into gaseous phase.

fractions in crude oil; these fractions have polar groups in their composition and are able to form stable emulsions.

It turns out that substances different in structure and properties are combined into one group of components, which burn down on the second peak of heat release by the reaction Coke $\rightarrow \mathrm{CO}_{2}+\mathrm{CO}+\mathrm{H}_{2} \mathrm{O}$. In terms of the produced set of equations this reaction is the continuation of reaction $\left(8^{\prime}\right)$ :

$$
2 \mathrm{RO}_{2}^{*}+\operatorname{Ing} \stackrel{k_{8}}{\longrightarrow} \text { Ing }^{*}
$$

The heat release at each of the stages described below is given in Table $1[16,17]$. 
TABLE 1: Heat release of oxidation reactions.

\begin{tabular}{lc}
\hline Heat release of the peroxidation reaction & $105-146 \mathrm{~kJ} / \mathrm{mol}$ \\
Heat release of the alcohol-formation reaction & $293-377 \mathrm{~kJ} / \mathrm{mol}$ \\
In the formation of CO, aldehydes, and & $356-398 \mathrm{~kJ} / \mathrm{mol}$ \\
ketones & \\
$\begin{array}{l}\text { In case of complete combustion and oxidation } \\
\text { to } \mathrm{CO}_{2}, \mathrm{H}_{2} \mathrm{O}\end{array}$ & $440 \mathrm{~kJ} / \mathrm{mol}$ \\
\hline
\end{tabular}

These values are important for the further "connection" of experimental data on heat release in the DSC with reactions described below.

\section{Equation System of Radical Chain Oxidation of Oil}

Thus the set of main oxidation reactions $\left(\left(1^{\prime}\right)-\left(9^{\prime}\right)\right)$ is formed. Initiation rate is $k_{1}$, chain transfer rates are $k_{2}, k_{3}$, and $k_{7}$, chain branching rates are $k_{4}$ and $k_{5}$ (hydrocarbon oxidation is a chain mechanism with degenerate branching), and $k_{6}, k_{8}$, and $k_{9}$ are chain termination rates.

At present, the oxidation of paraffinic hydrocarbons is considered to be the most studied process. Experiments on the oxidation of crude oil paraffinic hydrocarbons and synthetic paraffins were carried out repeatedly on a differential scanning calorimeter under pressure for studying of in situ combustion mechanisms [15].

Paraffinic hydrocarbons comprise $70-75 \%$ of the oil composition; the remaining $20 \%$ are aromatic compounds and 5$10 \%$ are resins and asphaltenes. In [11] crude oil separates into the main oxidizing components, alkanes and their oxidation inhibitors, aromatic compounds, which then form the fuel.

Then kinetic regularities of oxidation are studied using reactions on example of paraffinic hydrocarbons oxidation and all other components, without specifying their structure. For paraffinic hydrocarbons it is proved that hydroperoxides are the only primary oxidation products.

Crude oil oxidation mechanism can be written as scheme comprising main stages of paraffins oxidation, intermediate compounds, $\mathrm{R}^{*}, \mathrm{RO}^{*}, \mathrm{RO}_{2}^{*}$ radicals, peroxide $\mathrm{P}$, and a stage of free radical destruction on oxidation inhibitors Ing [11, 17]. The inhibitors are aromatic, resin, and asphaltene fractions of oil; they contain a number of compounds capable of inhibiting the process of oil oxidation.

Usually, the following approximations are used to simplify the system of equations [11].

(1) Activity of any alkoxy $\mathrm{RO}^{*}$ radicals is equal to activity of the hydroxyl ${ }^{*} \mathrm{OH}$ radical, which suggests that these particles are indistinguishable and rewrite reaction $\left(4^{\prime}\right)$ in the form: $\mathrm{P} \stackrel{k_{4}}{\longrightarrow} 2 \mathrm{RO}^{*}$.

(2) $\mathrm{HO}_{2}^{*}$ radicals are low-active and are not included in the reaction scheme.

(3) Stage $\left(2^{\prime}\right)$ is instantaneous; all alkyl $\mathrm{R}^{*}$ radicals are turning into $\mathrm{RO}_{2}^{*}$ radicals. The following approximation is described in [10]; for the same reason the products of reaction $\left(5^{\prime}\right)$ are similar to the products of reaction $\left(4^{\prime}\right)$ apart water output.

(4) $\mathrm{RO}^{*}$ radicals are much more active than $\mathrm{RO}_{2}^{*}$ radicals in the stage of the hydrogen atoms separation from the hydrocarbon molecules; hydroperoxyl $\mathrm{RO}_{2}^{*}$ radicals are more stable in comparison with alkoxy radicals.

Besides the chain branching, hydroperoxides can undergo transformations at higher temperatures by nonradical mechanism $\left(6^{\prime}\right)$ with complete combustion to $\mathrm{CO}_{2}$ and water.

Aromatic hydrocarbons act as inhibitors of the initial stages of oxidation [18]. Such compounds are able to catch the free radicals generated at the initiation stage, while also transforming into highly stable radicals, which are not able to continue further chain growth, reaction $\left(8^{\prime}\right)$; this is an oxygenation reaction without further development of combustion, which leads to high-molecular residue. Final reaction of the fuel combustion can be written as $\left(9^{\prime}\right)$.

The reaction rates are expressed by the Arrhenius law.

$$
k_{i}=A_{0 i} \cdot \exp \left(-\frac{E_{i}}{\mathrm{RT}}\right)
$$

The system of differential equations for the reaction scheme $\left(1^{\prime}\right)-\left(9^{\prime}\right)$ can be written as

$$
\begin{aligned}
& \frac{\partial}{\partial t}\left(C_{\mathrm{O}_{2}}\right)=-k_{1} C_{\mathrm{Oil}} C_{\mathrm{O}_{2}}-k_{2} C_{\mathrm{R}} C_{\mathrm{O}_{2}}-k_{9} C_{\mathrm{Ing}^{*}} C_{\mathrm{O}_{2}} \\
& \frac{\partial}{\partial t}\left(C_{\mathrm{Oil}}\right)=-k_{1} C_{\mathrm{Oil}} C_{\mathrm{O}_{2}}-k_{3} C_{\mathrm{Oil}} C_{\mathrm{RO}_{2}}-k_{5} C_{\mathrm{Oil}} C_{\mathrm{P}} \\
& -k_{7} C_{\mathrm{Oil}} C_{\mathrm{RO}} \\
& \frac{\partial}{\partial t}\left(C_{\mathrm{P}}\right)=k_{3} C_{\mathrm{Oil}} C_{\mathrm{RO}_{2}}-\left(k_{4}+k_{6}+k_{5} C_{\mathrm{Oil}}\right) C_{\mathrm{P}}
\end{aligned}
$$

And for the radicals:

$$
\begin{aligned}
& \frac{\partial}{\partial t}\left(C_{\mathrm{R}}\right)=k_{1} C_{\mathrm{O}_{i 1}} C_{\mathrm{O}_{2}}+k_{3} C_{\mathrm{Oil}} C_{\mathrm{RO}_{2}}-k_{2} C_{\mathrm{R}} C_{\mathrm{O}_{2}} \\
& +k_{5} C_{\mathrm{Oil}} C_{\mathrm{P}}+k_{7} C_{\mathrm{Oil}} C_{\mathrm{RO}} \\
& \frac{\partial}{\partial t}\left(C_{\mathrm{RO}}\right)=k_{4} C_{\mathrm{P}}+k_{5} C_{\mathrm{P}} C_{\mathrm{Oil}}-k_{7} C_{\mathrm{Oil}} C_{\mathrm{RO}} \\
& \frac{\partial}{\partial t}\left(C_{\mathrm{RO}_{2}}\right)=k_{2} C_{\mathrm{R}} C_{\mathrm{O}_{2}}-k_{3} C_{\mathrm{Oil}} C_{\mathrm{RO}_{2}}-k_{8} C_{\mathrm{Ing}} C_{\mathrm{RO}_{2}}
\end{aligned}
$$

Bodenstein's principle of quasi-stationary concentration can be applied to the equations with radicals (5) because reaction rate of radical formation is much lower than the rate of radical's decay. The bulk of the reaction occurs with the intermediate product under its constant concentration. The equations can be converted into algebraic form and solved relatively to concentration of peroxide.

$$
\begin{aligned}
& k_{0} C_{\mathrm{Oil}} C_{\mathrm{O}_{2}}+k_{2} C_{\mathrm{Oil}} C_{\mathrm{RO}_{2}}-k_{1} C_{\mathrm{R}} C_{\mathrm{O}_{2}}+k_{4} C_{\mathrm{Oil}} C_{\mathrm{RO}}=0 \\
& k_{3} C_{\mathrm{P}}-k_{4} C_{\mathrm{Oil}} C_{\mathrm{RO}}=0 \\
& k_{1} C_{\mathrm{R}} C_{\mathrm{O}_{2}}-k_{2} C_{\mathrm{Oil}} C_{\mathrm{RO}_{2}}-k_{5} C_{\mathrm{RO}_{2}}^{2}-k_{7} C_{\mathrm{Ing}} C_{\mathrm{RO}_{2}}=0
\end{aligned}
$$


To solve (4) in an explicit form it is necessary to express the concentration of $\mathrm{RO}_{2}^{*}$ radicals through the concentration of peroxides.

$$
\begin{aligned}
C_{\mathrm{RO}} & =\frac{k_{4} C_{\mathrm{P}}}{k_{7} C_{\mathrm{Oil}}}+\frac{k_{5} C_{\mathrm{P}}}{k_{7}} \\
C_{\mathrm{RO}_{2}} & =\frac{k_{3} C_{\mathrm{Oil}}}{k_{8} C_{\text {Ing }}}\left(k_{1} C_{\mathrm{Oil}} C_{\mathrm{O}_{2}}+C_{\mathrm{P}}\left(2 k_{5} C_{\mathrm{Oil}}+k_{4}\right)\right)
\end{aligned}
$$

The differential equation for the peroxide (4) can be written as

$$
\begin{aligned}
\frac{\partial}{\partial t}\left(C_{\mathrm{P}}\right)= & \frac{k_{3} C_{\mathrm{Oil}}}{k_{8} C_{\text {Ing }}}\left(k_{1} C_{\mathrm{Oil}} C_{\mathrm{O}_{2}}+C_{\mathrm{P}}\left(2 k_{5} C_{\mathrm{Oil}}+k_{4}\right)\right) \\
& -\left(k_{4}+k_{6}+k_{5} C_{\mathrm{Oil}}\right) C_{\mathrm{P}}
\end{aligned}
$$

Now, in order to solve the equation explicitly, we assume a constant concentration of oil, oxygen, and inhibitor during the time of peroxides accumulation. Let us denote $f=$ $\left(k_{3} C_{\text {Oil }} / k_{8} C_{\text {Ing }}\right)\left(2 k_{5} C_{\text {Oil }}+k_{4}\right)$ where chain growth factor is determined by the rate of hydroperoxides formation and radical decomposition, $g=k_{4}+k_{6}+k_{5} C_{\text {Oil }}$ where interruption factor is determined by all the decomposition types of reactions, and $\varphi=f-g$ where factor of degenerate branching is determined according to Semenov's theory [14].

$$
\frac{\partial}{\partial t}\left(C_{\mathrm{P}}\right)=\varphi C_{\mathrm{P}}+\frac{k_{3} C_{\mathrm{Oil}}}{k_{8} C_{\mathrm{Ing}}} k_{1} C_{\mathrm{O}_{2}} C_{\mathrm{Oil}}
$$

The rate of initiation $k_{1} C_{\mathrm{O}_{2}} C_{\mathrm{Oil}}=v_{0}$ is also assumed to be constant for the considered period of time.

Equation (10) can be integrated: $\int_{0}^{C_{\mathrm{p}}} \partial C_{\mathrm{P}} /\left(\varphi C_{\mathrm{P}}+\left(k_{3} C_{\mathrm{Oil}}\right)\right.$ $\left.\left.k_{8} C_{\text {Ing }}\right) v_{0}\right)=\int_{0}^{t} \partial t$.

After calculation of the integrals, we obtain the time dependence of hydroperoxides

$$
\ln \left(1+\frac{\varphi C_{\mathrm{P}}}{\left(k_{3} C_{\text {Oil }} / k_{8} C_{\text {Ing }}\right) v_{0}}\right)=\varphi t
$$

from which the concentration of peroxide is expressed by the formula:

$$
\varphi C_{\mathrm{P}}=\frac{k_{3} C_{\mathrm{Oil}}}{k_{8} C_{\text {Ing }}} v_{0}[\exp (\varphi t)-1]
$$

On the other hand the oxidation mechanism is such that all of the products are formed through the stage of peroxides; therefore we can write

$$
\begin{aligned}
\frac{\partial}{\partial t}\left(C_{\mathrm{CO}_{2}}\right) & =k_{1 \mathrm{P}} C_{\mathrm{P}} \\
\frac{\partial}{\partial t}\left(C_{\mathrm{CO}}\right) & =k_{2 \mathrm{P}} C_{\mathrm{P}} \\
\frac{\partial}{\partial t}\left(C_{\mathrm{H}_{2} \mathrm{O}}\right) & =k_{3 \mathrm{P}} C_{\mathrm{P}} \\
\frac{\partial}{\partial t}\left(C_{\mathrm{R}}\right) & =k_{4 \mathrm{P}} C_{\mathrm{P}} \\
k_{1 \mathrm{P}}+k_{2 \mathrm{P}}+k_{3 \mathrm{P}}+k_{4 \mathrm{P}} & =k_{6}
\end{aligned}
$$

Heat release is connected with the decomposition of peroxide and thus start of paraffins heat release (in case

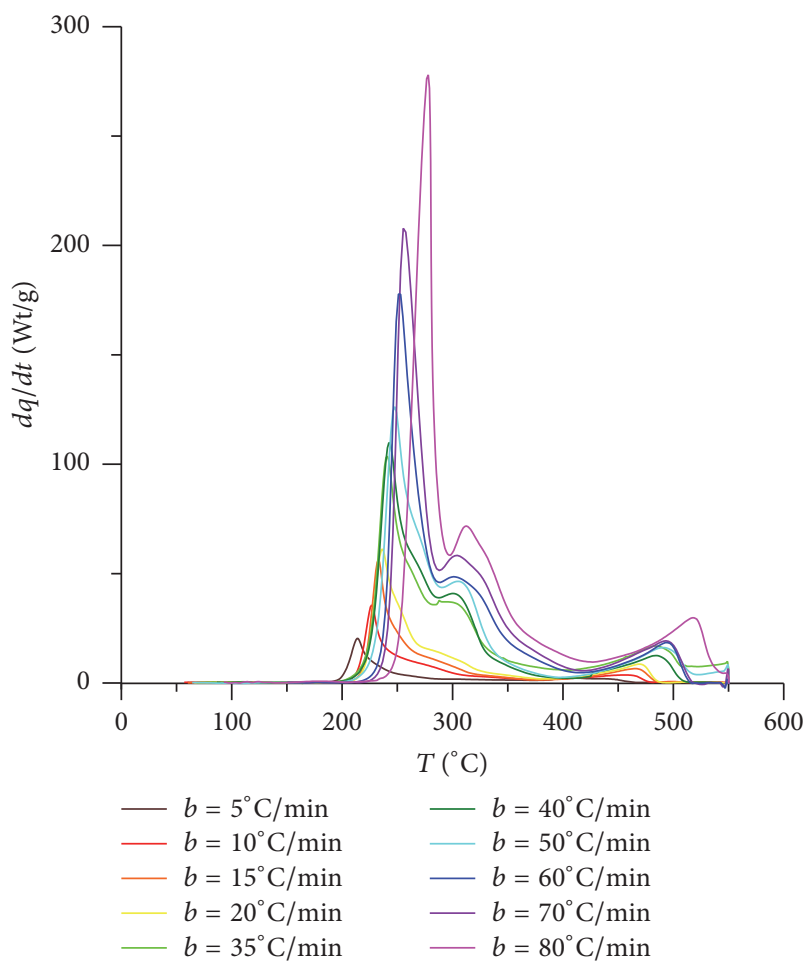

FIGURE 4: Kinetic curves of oil paraffins oxidation in DSC at a pressure of $5 \mathrm{MPa}$ and different heating rates $b$.

when the inhibition rate exceeds the rate of nonradical decomposition of peroxides, ignition chain case) must have an exponential dependence on time, where the coefficient of the exponent $\varphi$ in (12) is close to zero.

Heat release is connected with the decomposition of peroxide and thus start of paraffins heat release (in case when the inhibition rate exceeds the rate of nonradical decomposition of peroxides, ignition chain case) must have an exponential dependence on time, where the coefficient of the exponent $\varphi$ factor is close to zero (12).

This dependence is observed experimentally for paraffins (Figure 4) and crude oil in presence of cuttings (Figure 5) in the temperature range of $180-220^{\circ} \mathrm{C}$.

$$
\begin{aligned}
& \frac{d q}{d t} \sim A e^{\varphi t}, \\
& \varphi_{\text {sat }}=0.016 \pm 0.002 c^{-1} .
\end{aligned}
$$

Constant oil concentration and the inhibitor condition are fulfilled (the degree of transformation in considered reaction site does not exceed 10\%) and the constancy of oxygen concentration is provided by the experimental conditions on the DSC.

To prove the existence of a chain reaction mechanism on the stage of the first peak of heat release $\left(180-280^{\circ} \mathrm{C}\right)$ experimental kinetic curves are shown as a function $\ln (d q / d t)$ of the time $t$ (Figure 6), which are characterized by fairly constant positive slope of the initial straight section. Exactly the same dependence shows integral curves and the time derivative of the kinetic curves. 
TABLE 2: The values of the exponent in Semenov's formula for acceleration rate of oxidation reaction at the initial stage of the process.

\begin{tabular}{lcc}
\hline Heating rate, ${ }^{\circ} \mathrm{C} / \mathrm{min}$ & $\begin{array}{c}\text { The exponent in Semenov's formula } \\
\text { For the oxidation } \\
\text { rate }\end{array}$ & $\begin{array}{c}\text { For the oxidation } \\
\text { acceleration }\end{array}$ \\
\hline 5 & 0.01760 & 0.017 \\
10 & 0.01760 & 0.0193 \\
15 & 0.01710 & 0.0178 \\
20 & 0.01610 & 0.0162 \\
35 & 0.01200 & 0.0131 \\
40 & 0.01330 & 0.0117 \\
50 & 0.01210 & 0.0126 \\
60 & 0.01790 & 0.018 \\
70 & 0.01690 & 0.0167 \\
80 & 0.02000 & 0.02 \\
\hline Avg. value & $0.0161 \pm 0.0025$ & $0.0162 \pm 0.0027$ \\
\hline
\end{tabular}

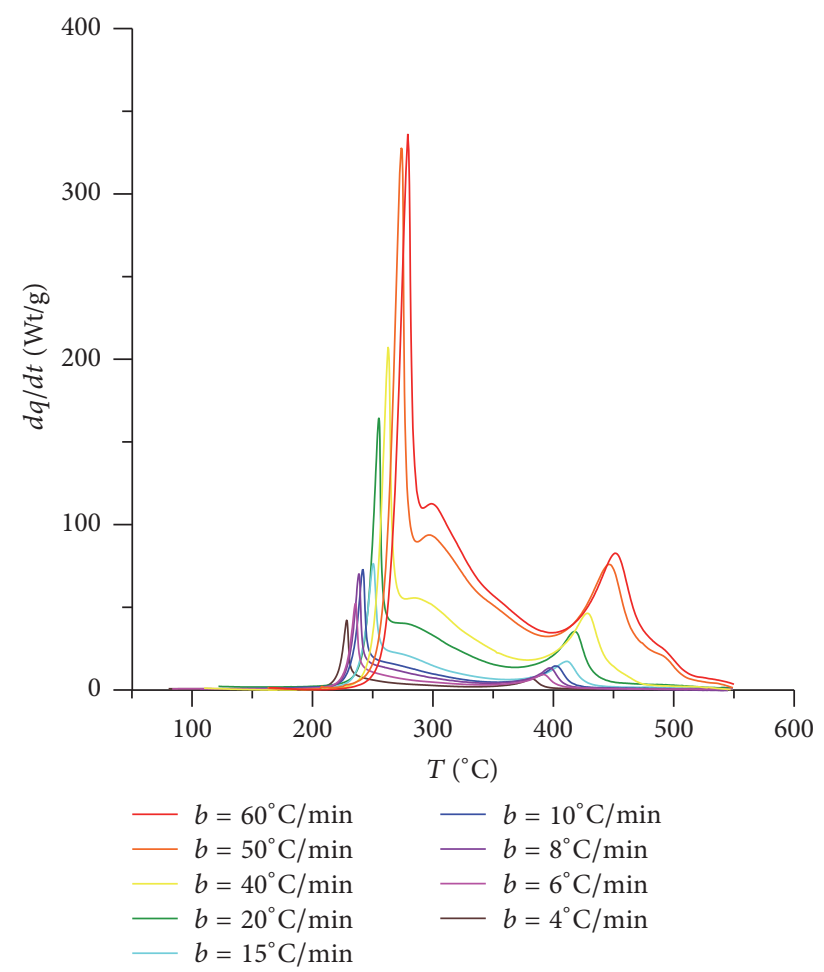

FIGURE 5: Kinetic curves of light oil oxidation adsorbed on crushed carbonate rocks in the DSC at a pressure of $5 \mathrm{MPa}$.

The values of the exponent in the Semenov's formula (14) for acceleration rate of oxidation reaction at the initial stage of the process are given in Table 2 .

\section{Identification of Chain Ignition Conditions from Reaction Equation}

Differential equation (10) was solved under the assumption that the $\varphi$ coefficient is positive. That is, the

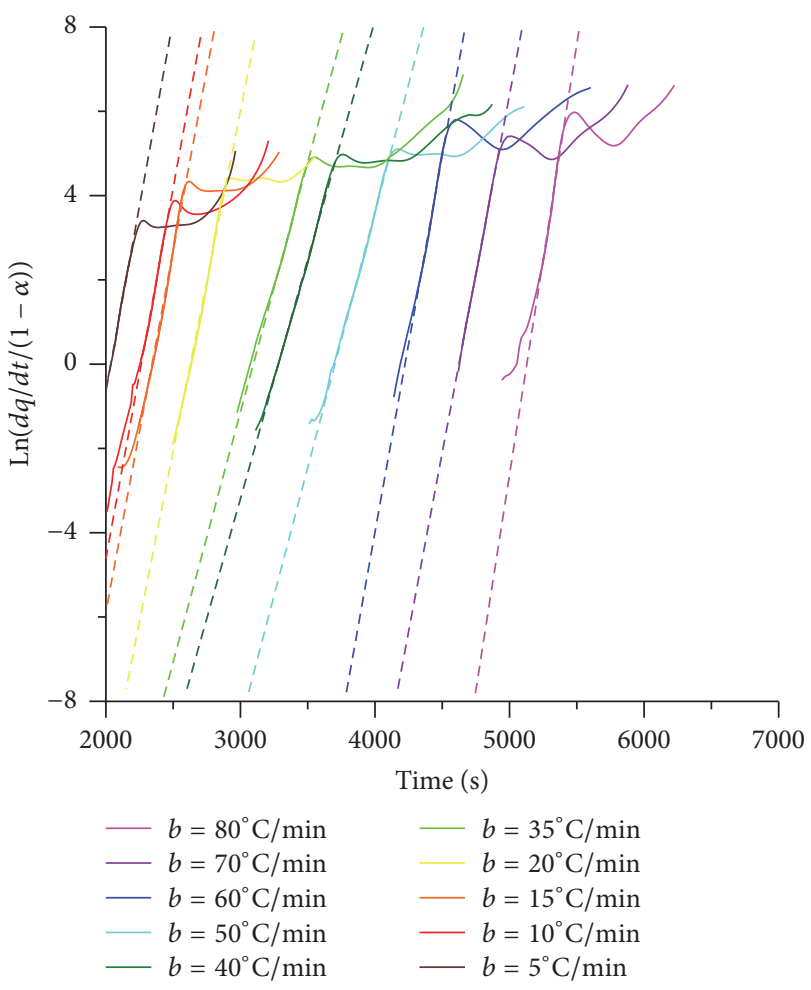

FIGURE 6: Dependence of natural logarithm of oxidation reaction rate on time for paraffins.

chain growth factor exceeds the interruption factor. $f=\left(k_{3} C_{\text {Oil }} / k_{8} C_{\text {Ing }}\right)\left(2 k_{5} C_{\text {Oil }}+k_{4}\right)>g=k_{4}+k_{6}+k_{5} C_{\text {Oil }}$, $g-f=\varphi>0$. This is the requirement of chain ignition.

If chain termination factor exceeds chain growth factor, then the chains are spent on inhibitors due to formation of peroxides; steady-state concentration of inactive peroxides is achieved and ignition does not occur as it occurs by a different mechanism. Let us write the condition of the chain ignition assuming that reactions $\left(5^{\prime}\right)$ and $\left(4^{\prime}\right)$ have similar rates at the initial stages $k_{4} \approx k_{5}$.

Let us suppose that at the initial moment in time the amount of inhibitor is enough so condition (15) fails.

$$
k_{3} k_{4} C_{\text {Oil }}\left(2 C_{\text {Oil }}+1\right) \geq k_{6} k_{8} C_{\text {Ing }}
$$

Let us write the differential equation for the consumption of the inhibitor: $(\partial / \partial t)\left(C_{\text {Ing }}\right)=-k_{8} C_{\text {Ing }} C_{\mathrm{RO}_{2}}$. Substituting (8) and (12) into (16) we obtain

$$
\begin{aligned}
& \frac{\partial}{\partial t}\left(C_{\text {Ing }}\right)=-k_{3} C_{\text {Oil }} v_{0}(1 \\
& \left.\quad+\frac{k_{3} C_{\text {Oil }}}{\varphi k_{8} C_{\text {Ing }}}\left(2 k_{5} C_{\text {Oil }}+k_{4}\right)[\exp (\varphi t)-1]\right)
\end{aligned}
$$

As in the previous section, we believe that before the beginning of the intensive consumption of oxygen concentrations of oil and oxygen are constant. At $\varphi$, factor close to zero, the second term in formulae (16) also tends to zero.

$$
\frac{\partial}{\partial t}\left(C_{\text {Ing }}\right)=-v_{0}
$$




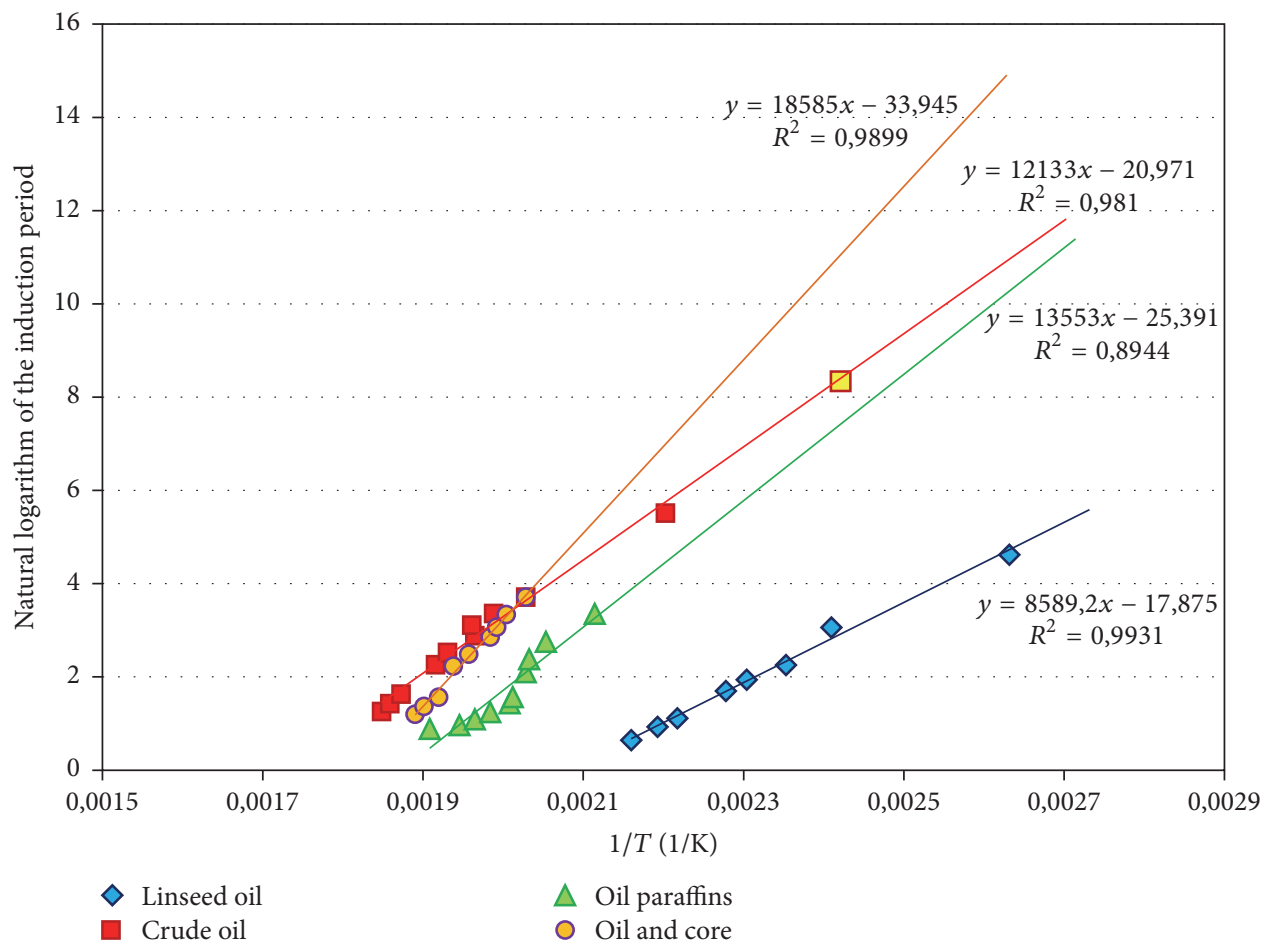

FIGURE 7: Dependence of the natural logarithm of crude oil heating time from the reverse temperature of self-ignition, obtained in PDSC experiments of oxidation. The yellow box is the data obtained from ARC experiment, which agree with DSC data.

Let us determine the inhibitor consumption time until the moment of ignition:

$$
\begin{aligned}
\int_{C_{\text {Ing }}{ }^{0}}^{C_{\text {In* }}} \partial C_{\mathrm{P}} & =-v_{0} \int_{0}^{\tau_{\text {Ind }}} \partial t \\
\Delta C_{\text {Ing }} & =-A_{0} C_{\mathrm{O}_{2}} C_{\text {Oil }} \exp \left(\frac{E_{0}}{\mathrm{RT}}\right) \tau_{\text {Ind }}
\end{aligned}
$$

Induction time depends on the temperature:

$$
\begin{aligned}
\frac{\Delta C_{\text {Ing }}}{A_{0} C_{\mathrm{O}_{2}} C_{\text {Oil }}} & =\exp \left(-\frac{E_{0}}{\mathrm{RT}}\right) \tau_{\text {Ind }} \\
\ln \tau_{\text {Ind }} & =\ln \frac{\Delta C_{\text {Ing }}}{A_{0} C_{\mathrm{O}_{2}} C_{\mathrm{Oil}}}+\frac{E_{0}}{\mathrm{RT}}
\end{aligned}
$$

Linear dependence of ignition time from reciprocal temperature is observed experimentally during the oxidation of the oil in the PDSC (initial point is the moment when the tangent to a heat release curve on the DSC becomes inclined, Figures 4 and 5). The slope of the line describes the activation energy for the initiation stage, and the free term describes the logarithm of the concentrations ratio of oxygen, crude oil, and inhibitor.

Figure 7 shows the above relationships for crude oil, paraffins, and linseed oil. The slope of the lines does not change greatly, and the value on the $x$-axis is moved. The greater the proportion of the inhibitor is, the greater the induction period characterizing the time of binding the inhibitor to oxygen is. Oil paraffins have a minimum fraction of the inhibitor in its composition, proportional to degree of their purification.

Oil on the rock is characterized by smaller fraction of the inhibitor as compared with pure oil due to inhibitor adsorption. Paraffins have an even smaller fraction of inhibitor in its composition.

Let us add another reaction to describe the second peak of heat release, combustion of inhibitors, which formed the fuel. This reaction occurs at a temperature of $350-400^{\circ} \mathrm{C}$ :

$$
\begin{aligned}
\frac{\partial}{\partial t}\left(C_{\text {Ing }}^{*}\right) & =C_{\text {Ing }}^{*} k_{7}-C_{\mathrm{O}_{2}} C_{\text {Ing }}^{*} k_{8} \\
\frac{d\left(C_{\text {Ing }}^{*}\right)}{C_{\text {Ing }}^{*}} & =\left(k_{7}-C_{\mathrm{O}_{2}} k_{8}\right) d t, \\
C_{\text {Ing }}^{*} & =\exp \left(k_{7}-C_{\mathrm{O}_{2}} k_{8}\right) t
\end{aligned}
$$

The analysis shows that the concentration of oxidized inhibitor (fuel) increases until the formation rate exceeds the consumption rate; then fuel consumption goes up exponentially in time.

\section{Correlation of Radical Chain Oxidation of Crude Oil Equations with Heat Release Data Obtained by the PDSC}

Reaction equations can be related to heat release of oil combustion on the PDSC due to the accuracy and small reactivity of the method of differential scanning calorimetry. 


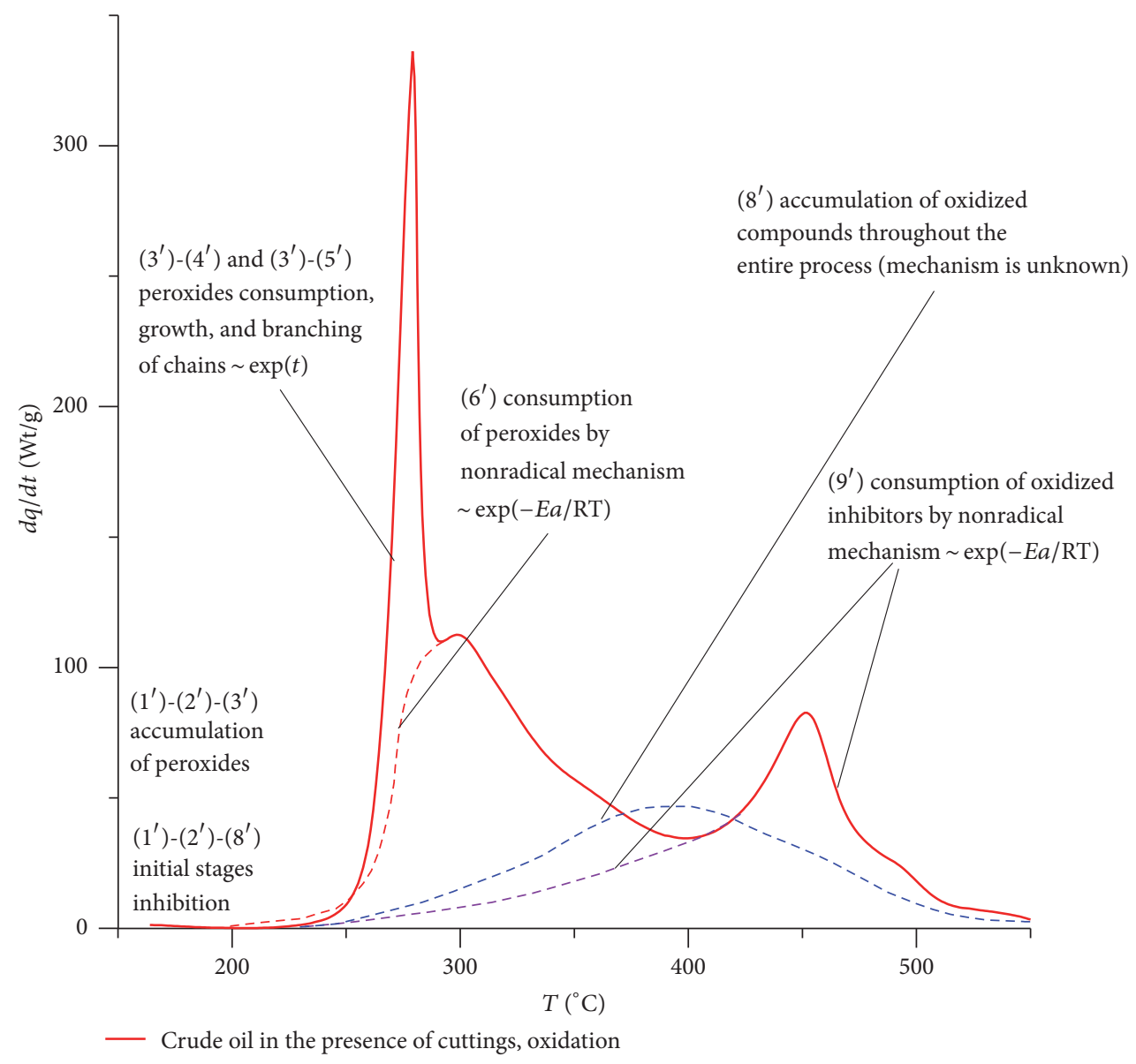

FIGURE 8: Distribution of examined oxidation processes according to heat release curve on the DSC.

As it can be seen from Figures 4 and 5, the heat release from the oil in presence of core samples and oil paraffins oxidation has two peaks; the first peak is divided on the time and temperature components studied in [15]; schematic separation of the first peak in two separate peaks is shown in Figure 8.

(1) The induction period occurs almost without heat generation and goes through a chain of reactions $\left(1^{\prime}\right) \rightarrow\left(2^{\prime}\right) \rightarrow\left(8^{\prime}\right)$ until inhibitors will be spent; at the same time there is an accumulation of peroxides by the reaction $\left(1^{\prime}\right) \rightarrow\left(2^{\prime}\right) \rightarrow\left(3^{\prime}\right)$. The induction period is associated with the rate of initiation, rate of inhibitor consumption, and temperature (18).

(2) The first massive bond breaking after the induction period is caused by the exponential increase of peroxides concentration (12) when the condition of chain ignition is fulfilled (14) and then also due to exponential growth of heat release from decomposition of peroxides $\left(3^{\prime}\right) \rightarrow\left(4^{\prime}\right)$ and $\left(3^{\prime}\right) \rightarrow\left(5^{\prime}\right)$.

(3) Temperature rises in the process of exponential growth of heat release in time, so nonradical decomposition of peroxides becomes possible $\left(6^{\prime}\right)$. This decomposition is characterized by Arrhenius dependence in the temperature range of $250-300^{\circ} \mathrm{C}$. It is most likely a decomposition of linear peroxides and linear tails of aromatics by nonradical mechanism; $\mathrm{CO}, \mathrm{CO}_{2}$, and $\mathrm{H}_{2} \mathrm{O}$ are released during the process.

(4) At higher temperatures $\left(300-350^{\circ} \mathrm{C}\right)$ there begin reactions of isomerization and cyclization with a separation of linear molecules tailings, separation of hydrogen, and oxidation of these tailings, which turn into $\mathrm{CO}$ and $\mathrm{CO}_{2}$, respectively. This stage is also accompanied by the formation of coke and a negative temperature gradient $\left(8^{\prime}\right)$. And then at the second combustion peak occurs by the reaction $\left(9^{\prime}\right)$.

This last stage, the combustion of coke, takes place during the oxidation of any crude oil containing a minimum quantity of initial stages inhibitors: aromatics, resins, and asphaltenes.

Thus, the connection stage between LTO and the HTO is a generalized reaction $\left(8^{\prime}\right)$, which depends on the initial amount of oil inhibitors (aromatics). This reaction takes place during the entire process of oxidation, at any temperature. Initially this reaction inhibits initial steps of oxidation; oxygen is absorbed in this reaction due to the appearance of inactive radicals. Then, molecular weight of crude oil increases with the rise of temperature and a transition of the resins into secondary asphaltenes occurs, which also contributes to the formation of fuel. The oxidized oil is 
adsorbed onto the rock surface, and then the combustion of oxidized components takes place.

\section{Conclusions}

The theory of radical chain oxidation of hydrocarbons is used to describe the self-ignition of oil in the reservoir.

It is shown that crude oil as a mixture of hydrocarbons of various structures can be oxidized by a radical chain mechanism at low temperatures, as well as by the nonradical decomposition. Chain mechanism, investigated using the theory of Semenov, is clearly evident at the initial stages of oxidation. It is shown that ignition is the result of free radicals' formation and destruction processes. A chain reaction of oxidation with heat release starts when the amount of radicals produced per unit of time exceeds the number of decomposed ones. Then this reaction turns into nonradical combustion reaction.

Otherwise accumulated radicals do not initiate inflammation. Destruction of free radicals occurs on inhibitors of initial stages of oxidation: molecules, resins, and asphaltenes. Aromatic molecules, capturing the free radicals, remove them from oxidation process up to temperatures of $300-350^{\circ} \mathrm{C}$. Thus, in the process of combustion initiation $\left(150-200^{\circ} \mathrm{C}\right)$ and the low-temperature oxidation $\left(250-300^{\circ} \mathrm{C}\right)$ accumulation of fuel for high-temperature combustion occurs.

We have proposed equation system for oxidation reactions, including the radical chain mechanism. Level of model detail allows obtaining analytically basic experimentally observed dependences and the types of reactions occurring.

\section{Competing Interests}

The authors declare that there is no conflict of interests regarding the publication of this paper.

\section{Acknowledgments}

The work has been performed according to the Russian Government Program of Competitive Growth of Kazan Federal University.

\section{References}

[1] P. S. Sarathi, In-Situ Combustion Handbook-Principles and Practices, BDM Petroleum Technologies, 1999.

[2] A. T. Turta, S. K. Chattopadhyay, R. N. Bhattacharya, A. Condrachi, and W. Hanson, "Current status of commercial in situ combustion projects worldwide," Journal of Canadian Petroleum Technology, vol. 46, no. 11, pp. 8-14, 2007.

[3] H. J. Remy, "In-situ combustion," in Proceedings of the 8th World Petroleum Congress, Discussion Symposium, USSR, Moscow, Russia, June 1971.

[4] D. Gutiérrez, R. J. Miller, A. R. Taylor, B. P. Thies, and V. K. Kumar, "Buffalo field high-pressure-air-injection projects: technical performance and operational challenges," SPE Reservoir Evaluation and Engineering, vol. 12, no. 4, pp. 542-550, 2009.

[5] Y. G. Mamedov and A. A. Bokserman, "Application of improved oil recovery in Sovet Union," in Proceedings of the Enhanced Oil
Recovery Symposium, 24162-MS SPE, Tulsa, Okla, USA, April 1992.

[6] C. Chu, "A study of fireflood field projects (includes associated paper 6504)," Journal of Petroleum Technology, vol. 29, no. 2, pp. $111-120,1977$.

[7] T. M. Counihan, "A successful in-situ combustion pilot in the Midway-Sunset Field, California," in Proceedings of the SPE California Regional Meeting, SPE 6525, Bakersfield, Calif, USA, April 1977.

[8] A. N. Shandrygin and A. Lutfullin, "Current status of enhanced recovery techniques in the fields of Russia," in Proceedings of the SPE Annual Technical Conference and Exhibition (ATCE'08), pp. 1929-1946, Denver, Colo, USA, September 2008.

[9] D. G. Mallory, I. I. Abu, K. Fraassen, M. G. Ursenbach, R. G. Moore, and S. A. Mehta, "Accelerating Rate Calorimetry Tests West Salym Oil \& Core in Contact with Air," 2011.

[10] E. T. Denisov, Kinetics of Homogeneous Chemical Reactions, High School, Moscow, Russia, 1973 (Russian).

[11] N. P. Freitag, "Chemical-reaction mechanisms that govern oxidation rates during in-situ combustion and high-pressure air injection," SPE Reservoir Evaluation \& Engineering, vol. 19, no. 4, 2016.

[12] N. M. Emanuel, "Present state of the theory of chain reactions in the liquid phase oxidation of hydrocarbons," in Proceedings of the 7th World Petroleum Congress, Mexico City, Mexico, April 1967.

[13] K. U. Ingold, “Oxidation of organic compounds," in Oxidation of Organic Compounds, vol. 75 of Advances in Chemistry, chapter 23, pp. 296-305, American Chemical Society, 1968.

[14] N. Semenov, "Advances of chemical kinetics in the Soviet Union," Nature, vol. 151, no. 3824, pp. 185-187, 1943.

[15] V. A. Klinchev, V. V. Zatsepin, A. S. Ushakova, and S. V. Telyshev, "Laboratory studies and implementation of in-situ combustion initiation technology for air injection process in the oil reservoirs," Tech. Rep. SPE-171244, 2014.

[16] J. G. Burger and B. C. Sahuquet, "Chemical aspects of insitu combustion-heat of combustion and kinetics," Society of Petroleum Engineers Journal, vol. 12, no. 5, pp. 410-422, 1972.

[17] B. Sequera, R. G. Moore, S. A. Mehta, and M. G. Ursenbach, "Numerical simulation of in-situ combustion experiments operated under low temperature conditions," Journal of Canadian Petroleum Technology, vol. 49, no. 1, pp. 55-64, 2010.

[18] A. E. Shilov and G. B. Shul'pin, Activation and Catalytic Reactions of Saturated Hydrocarbons in the Presence of Metal Complexes, Kluwer Academic Publishers, London, UK, 2002. 


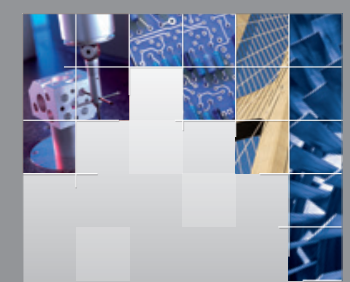

\section{Enfincering}
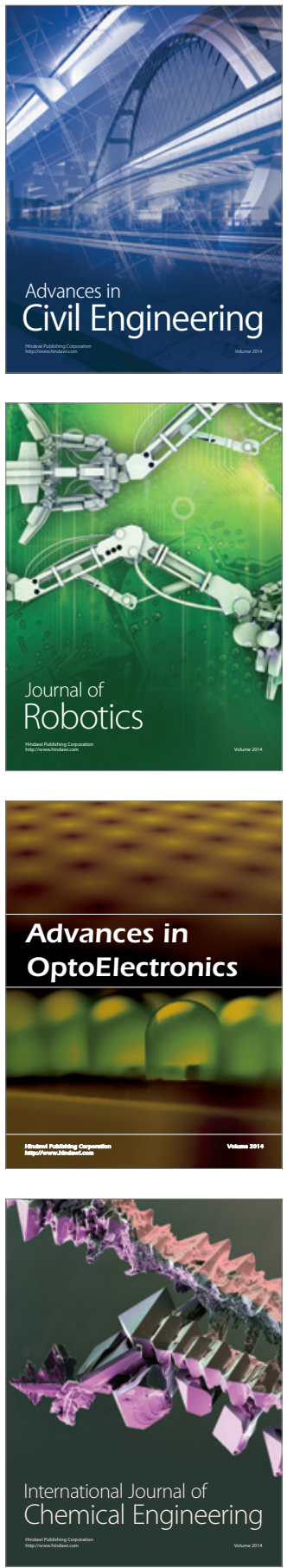

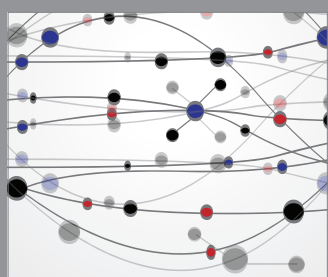

The Scientific World Journal

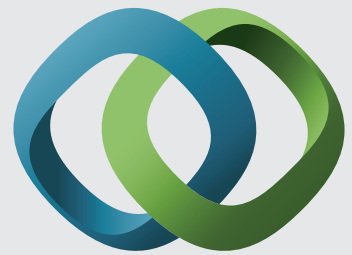

\section{Hindawi}

Submit your manuscripts at

https://www.hindawi.com
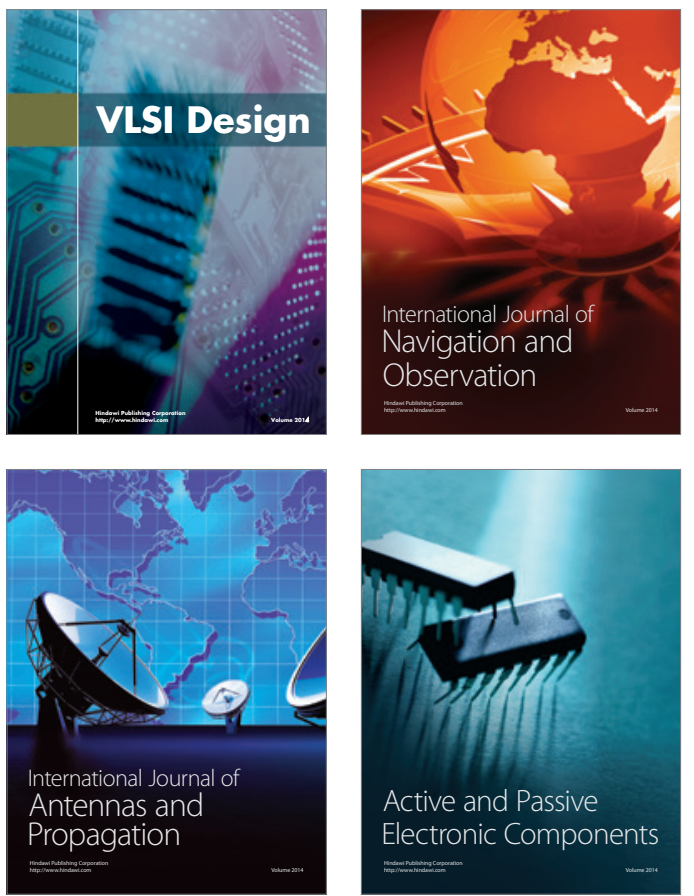
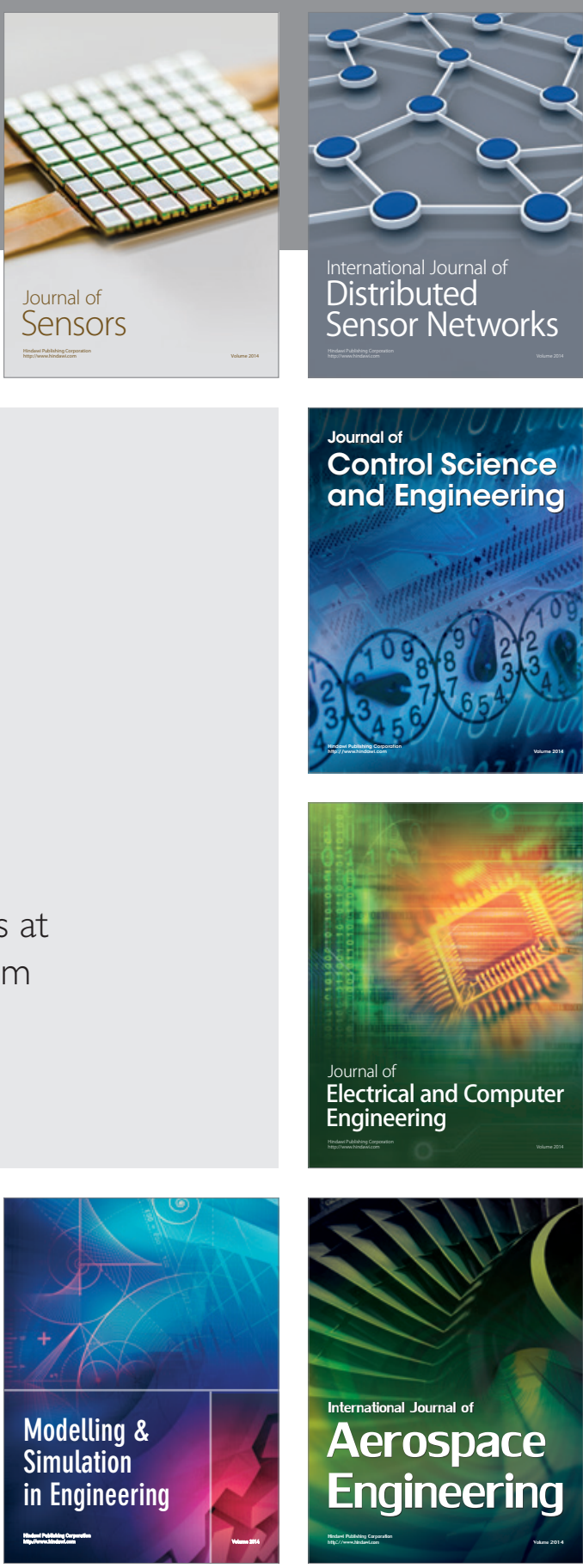

International Journal of

Distributed

Sensor Networks

$-$

Joumal of

Control Science

and Engineering
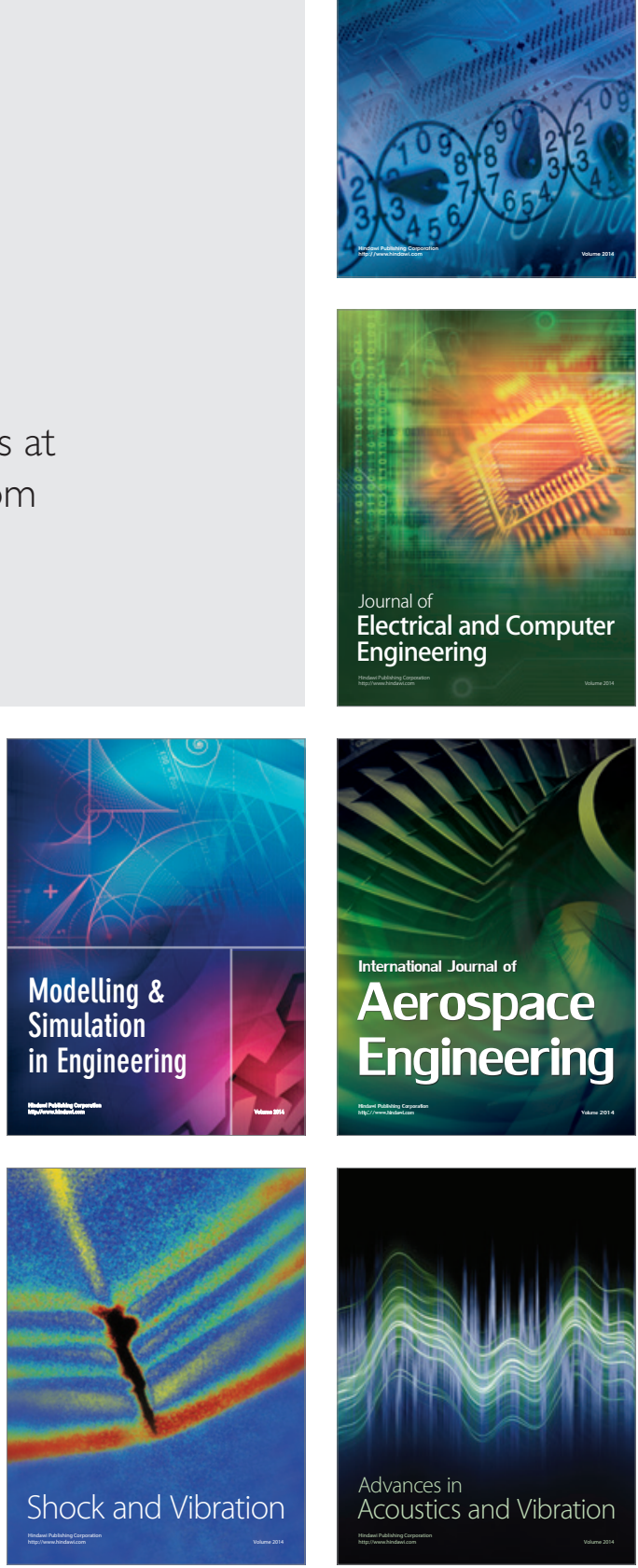